

\title{
ORTODOXIA Y HETERODOXIA EN LA ANDALUCIA OCHOCENTISTA
}

\author{
POR \\ José Manuel Cuenca Toribio \\ Universidad de Córdoba
}

Durante el siglo que hasta el momento consideramos, el primero de la contemporaneidad, el discurrir de la iglesia andaluza of rece algunas notas que la diferencian, relativamente, respecto a la evolución global del catolicismo hispano. Dichas características no realzan su presencia o aumentan su peso en la evolución religiosa del país; antes al contrario, la empujan a una cierta marginalidad y oscurecimiento' .

En un estudio dedicado al regionalismo meridional veíamos su retraimiento o, más exactamente, su apartamiento de los débiles brotes surgidos en la Andalucía de la segunda mitad del XIX en pro de una conciencia de autonomía. Esta ausencia, de escasa importancia y debido sin duda a la aún menor relevancia del fenómeno regionalista en las tierras del sur, sí resulta, en cambio, muy expresiva de la falta de vitalidad de una institución que, en Andalucia, presenta muy claramente los signos de enclaustramiento que el triunfo de las ideas y modos de vida del sistema liberal imprimieron en ella a toda la escala del país.

Dicha postración no tuvo su principal causa, como sucediera en otras regiones, en la hostilidad particular con que distinguieran a la iglesia andaluza

1 CUENCA TORIBIO, J.M. Iglesia y sociedad en la España del siglo XIX, Córdoba, 1980. 
las autoridades y prohombres del Nuevo Régimen. La práctica inexistencia del carlismo en el mediodía hace que la decadencia de la iglesia andaluza ochocentista tenga que atribuirse fundamentalmente a factores nacidos de su propia anemia espiritual. La conciencia victimal en ella no fue superior a la gallega, a la vasca, o, mucho menos a la catalana; pero su respuesta a la crisis provocada en el estamento eclesiástico por la victoria del liberalismo fue menor en todos los aspectos. Así lo testifica el que lo que cabría denominar en más de un sentido repoblación eclesiástica y, en buena medida también, espiritual, de las últimas decadas del XIX andaluz proviniese, como es sabido, del impulso extranjero o de órdenes y congregaciones nacidas en el norte del país; en tanto que la restauración religiosa emprendida al mismo tiempo y con idénticos objetivos por las comunidades eclesiásticas más tradicionales -jesuitas, franciscanos, dominicos, agustinos...- fue también obra casi exclusiva de hombres nacidos igualmente al norte de Despeñaperros.

En otros lugares de la nación, la iglesia contó con líderes que animaron y dirigieron su réplica al gran desafio del lento afianzamiento de un clima secularizador en la península. En Andalucía no se puede constatar dicho fenómeno. Cuando algún prelado de grandes dotes y capacidades lo intentó, bien que de manera casi indeficiente sin demasiadas energías físicas, sus proyectos y consignas se perdieron en el vacío de un catolicismo muy elementalizado y de muy escasa vitalidad ${ }^{2}$.

Esta atonía contrasta, un poco paradójicamente, con la potencia de lo que cabría llamar la "heterodoxia" andaluza. No es fácil conocer si el vigor de la última se debió a la debilidad de la primera; aunque, en todo caso, sí es claro que se aprovechó del innegable declive padecido por el catolicismo andaluz a lo largo del siglo XIX ${ }^{3}$.

Uno de los principales promotores de la heterodoxia decimonónica, el soriano Julián Sanz del Río (1814-1869), tuvo una prolongada y decisiva estancia cordobesa en su biografía. Mas tarde, el Krausismo y la Institución Libre de Enseñanza contaron en sus filas con un elenco nutrido y, sobre todo, des-

2 Vid. las excelentes contribuciones de FERRER BenimeLl, J.A. "Implantación de logias y distribución geográfico-histórica de la masonería espaŕola" en La masonería en la España del siglo XIX. Salamanca, I, 1987, en especial 71, 111-113, 159-160, 169.

3 ENRIQUeZ DEL ARBOL, E. " La masonería en Andalucía en el último tercio del siglo XIX. Listado y mapa de logias existentes en fechas puntuales (1870, 1876, 1887, 1895 y 1900). Problemática y rectificaciones", y vid, en particular, la valiosa obra de GAY ARMENTEROS, J. y PINTO MOLINA, M., La Masoneria en Andalucia Oriental a finales del siglo XIX. Jaén y Granada. Granada, 1983. Merece en especial destacarse el breve análisis de la composición de las logias, 420 y ss. La comunicación de López CASIMIRO, F. "Anselmo Arenas y la masonería granadina fínesecular" en Hespérides. VII Congreso de profesores-investigadores, Montilla, 1987, proporciona igualmente datos de gran interés sobre la Masonería granadina de fines del XIX. 261-62.

De la Iglesia Andaluza Hispania Sacra 48 (1996) 
collante de personalidades nacidas en el Sur. Desde Nicolás Salmerón y Francisco Giner de los Ríos hasta Alberto Jiménez Fraud y. La anglofilia, motor y vehículo esencial de la corriente modernizadora que atraviesa todos los movimientos reformadores de la vida nacional en la etapa contemporánea, encontró su principal cauce de expresión en las élites andaluzas en vanguardia de los cambios sociales e ideológicos. La figura del gaditano Segismundo Moret y Prendergart (1853-1912) resume, en su casi siempre brillante trayectoria política y cultural, dicho espíritu, al, mismo tiempo que sirve para introducir sin violencia alguna el aún controvertido tema de la masonería.

Las cuatrocientas logias asentadas en la Andalucía ochocentista -cifra igual a las de todo el resto de la nación- rompe sin ninguna duda no pocos clichés acerca de su fisonomía y trayectoria. No obstante, como ya señalábamos en otro trabajo, la exigüidad de muchos de estos núcleos masónicos y de la artificiosidad y coyunturalismo de una buena porción de ellos, el guarismo está ahí, irrebatible, y nos señala una propagación muy intensa, al menos geográficamente -en el último cuarto de siglo, Granada contaría con 21 establecimientos masónicos-, de la corriente espiritual más importante, cara a los contemporáneos, del mundo de la heterodoxia decimonónica ${ }^{4}$.

La más canónica modalidad de ésta a los ojos de los mismos coetáneos, la representada por las sectas protestantes, halló también una notable recepción andaluza, si no por el número de sus adeptos, si por los sucesos que jalonaron la carrera de sus principales apóstoles y proselitistas. Aún cuando algún perspicaz observador eclesiástico atribuyera el éxito -muy menguado, en términos númericos, convendrá insistir- a la falta de entusiasmo y preparación por parte del clero, acaso fuera más exacto el diagnóstico dado por otros comentaristas, de mediados y finales del siglo, de hallar en la indigencia de los estratos populares la clave principal del desvío, a menudo fugaz y transitorios de la religión tradicional de lado de algunos sectores del pueblo andaluz ${ }^{5}$.

4 Así lo acredita Ferrer Benimeli, J.A. en "El Grande Oriente Lusitano Unido y los masones españoles (1869-1878)" en La Masonería en la España del siglo XIX. Salamanca, II, 1987.

5 Cfr. CARCEL ORTI, V., León XIII y los calólicos españoles. Informes vaticonos sobre la iglesia en España., Pamplona, 1988, sobre todo, el amplio informe sobre las dibcesis españolas, redactado en Madrid el 31 de diciembre de 1890 por el futuro nuncio ante Alfonso XIlI y entonces funcionario de la Nunciatura, Antonio Vico. 